\title{
Eight Colletotrichum Species, Including a Novel Species, Are Associated With Areca Palm Anthracnose in Hainan, China
}

\author{
Xueren Cao, ${ }^{1, \dagger}$ Xiangming Xu, ${ }^{2}$ Haiyan Che, ${ }^{1}$ Jonathan S. West, ${ }^{3}$ and Daquan Luo ${ }^{1, \dagger}$ \\ ${ }^{1}$ Key Laboratory of Integrated Pest Management on Tropical Crops, Ministry of Agriculture, Environment and Plant Protection \\ Institute, Chinese Academy of Tropical Agricultural Sciences, Haikou 571101, China \\ ${ }^{2}$ NIAB EMR, East Malling, Kent ME19 6BJ, United Kingdom \\ ${ }^{3}$ Rothamsted Research, Harpenden AL5 2JQ, United Kingdom
}

\begin{abstract}
Genus Colletotrichum is one of the most important genera of plantpathogenic fungi affecting numerous species, particularly tropical and subtropical crops and fruit trees. In this study, 43 Colletotrichum strains were isolated from areca palm leaves with anthracnose symptoms in 11 areca palm plantations in eight counties of Hainan, China. Based on the morphology, phylogenetic analysis of six loci (internal transcribed spacer, actin, chitin synthase 1 , glyceraldehyde-3-phosphate dehydrogenase, $\beta$-tubulin, and mating type locus MAT1-2), and pathogenicity tests, eight Colletotrichum species were distinguished, comprising five previously known spe-

(C. arecicola) in the gloeosporioides species complex, and C. karstii in the boninense species complex. $C$. siamense was the most common species found in areca palm in Hainan, followed by $C$. arecicola. Pathogenicity tests showed that all eight species could cause anthracnose symptoms on areca palm leaves using a wound inoculation method and that the isolates from the gloeosporioides species complex caused larger lesions than the isolates from the boninense species complex. Further research is needed to understand the epidemiology of these pathogenic species on areca palm in order to develop management strategies.
\end{abstract} cies (C. cordylinicola, C. fructicola, C. gloeosporioides, C. siamense, and $C$. tropicale), one unidentified Colletotrichum species, a new species
Keywords: etiology, fungi, tropical plants
Areca palm (Areca catech $u$ L.; Arecaceae) originates from Malaysia and is widely distributed in the tropical regions of Asia, East Africa, and the Pacific (Srimany et al. 2016). Fruits of A. catechu (areca nut or betelnut) are popular chewable items and more than 400 million people chew betel quid daily in tropical and subtropical countries (Peng et al. 2015). A. catechu is also used in traditional herbal medicine. Investigations demonstrate that $A$. catech $u$ has various pharmacological activities, including antiparasitic, antioxidant, antibacterial, antifungal, anti-inflammatory, analgesic, and antiallergic effects and regulatory effects on blood glucose and lipids (Peng et al. 2015). China is the second largest producer of areca nut in the world, with $99 \%$ of its production in Hainan (Huang et al. 2016); areca palm is the second largest commercial crop in Hainan, where it is mainly planted in the eastern, central, and southern parts of the province.

A number of pathogens cause diseases on A. catechu at different growth stages. Anthracnose, caused by Colletotrichum spp., is an important disease on areca palm and the fungus can survive in the debris of the previous year's infected bunches for up to 8 months (Yashoda et al. 1992). In India, approximately $60 \%$ of the areca palms were affected by $C$. gloeosporloides (Lokesh et al. 2013), whereas the incidence of trees with anthracnose can reach $90 \%$ in Hainan where the

${ }^{\dagger}$ Corresponding authors: X. R. Cao; caoxueren1984@163.com, and D. Q. Luo; luodaquan@163.com

Funding: This work was financially supported by grants from the Natural Science Foundation of Hainan Province, China (2019RC277), the Hainan Major Research Fund of Science and Technology (ZDKJ201817), and the Central Public-Interest Scientific Institution Basal Research Fund for Chinese Academy of Tropical Agricultural Sciences (1630042017023).

*The $\boldsymbol{e}$-Xtra logo stands for "electronic extra" and indicates that one supplementary figure and one supplementary table are published online.

The author(s) declare no conflict of interest.

Accepted for publication 20 December 2019.

(C) 2020 The American Phytopathological Society disease is prevalent (Zhu et al. 2015). Morphology, pathogenicity, and rDNA-internal transcribed spacer (ITS) sequence analysis of a single isolate indicated that $C$. gloeosporioides was the pathogen causing areca anthracnose in Hainan (Zhu et al. 2015). However, the identification of Colletotrichum spp. based solely on morphology and ITS sequences has proven difficult (Ko Ko et al. 2011). With the use of multilocus phylogenetic analysis, 22 species and one subspecies were accepted within the $C$. gloeosporioides complex (Weir et al. 2012). Since then, several new species were reported as belonging to this species complex (Liu et al. 2015; Manamgoda et al. 2013). A recent review reported 38 closely related species in the gloeosporioides species complex (Marin-Felix et al. 2017).

The objectives of this study were as follows: (i) to characterize and identify the Colletotrichum species associated with anthracnose of areca palm in Hainan, China, using molecular and morphological analyses; and (ii) to assess the pathogenicity of these different Colletotrichum species on areca palm leaves.

\section{Materials and Methods}

The general experimental framework followed our previous work on characterization of Colletotrichum isolates from rubber trees and coffee in Hainan, China (Cao et al. 2019a, b).

Colletotrichum isolates. In 2018 to 2019, leaves with typical anthracnose symptoms were randomly collected from 11 areca plantations in eight counties in Hainan, China (Fig. 1); in total, 55 leaf samples were used for fungal isolation (four to seven samples for each plantation). Small pieces $(5 \times 5 \mathrm{~mm})$ of leaf tissues from the lesion margins were disinfected in $70 \%$ ethanol for $30 \mathrm{~s}$ and followed by $1 \mathrm{~min}$ in $1 \%$ sodium hypochlorite. Then these leaf pieces were washed three times with sterile distilled water for $30 \mathrm{~s}$ and finally plated on potato dextrose agar (PDA). The plates were incubated at room temperature $\left(28\right.$ to $\left.30^{\circ} \mathrm{C}\right)$ under laboratory lighting conditions; after 2 to 3 days, actively growing hyphal tips were transferred to new plates with fresh PDA.

A new species was identified in this study with its type specimen deposited in the Mycological Herbarium at the Institute of Microbiology, Chinese Academy of Sciences, Beijing, China (HMAS), and an ex-type living culture of this new species was deposited in the China General Microbiological Culture Collection Center (CGMCC), Beijing, China. 
Genomic DNA extraction, PCR, and sequencing. Mycelia from fresh colonies grown on PDA for 5 days at $25^{\circ} \mathrm{C}$ were harvested with a sterile $10-\mu l$ pipette tip. Total genomic DNA was extracted using the Tiangen Plant Genomic DNA Kit (Tiangen Biotech, Beijing, China) according to the manufacturer's instructions. Six genomic loci, including ITS, actin (ACT), $\beta$-tubulin (TUB2), chitin synthase 1 (CHS-1), glyceraldehyde-3-phosphate dehydrogenase (GAPDH), and the mating type locus MAT1-2 (ApMat), were amplified and sequenced using the following primer pairs, respectively: ITS-1/ITS-4 (Gardes and Bruns 1993 and White et al. 1990, respectively), ACT512F/ACT-783R (Carbone and Kohn 1999), T1/Bt2b (O'Donnell and Cigelnik 1997 and Glass and Donaldson 1995, respectively), CHS-79F/CHS-354R (Carbone and Kohn 1999), GDF1/GDR1 (Templeton et al. 1992), and AMF1/AMR1 (Silva et al. 2012).

PCR was performed in a thermal cycler (C1000; Bio-Rad Laboratories, Hercules, CA) in a $25-\mu$ l reaction volume, composed of $12.5 \mu \mathrm{l}$ of Taq-Plus PCR Forest Mix (NOVA, Yugong Biolabs, Jiangsu, China), $1 \mu \mathrm{l}$ of each primer $(5 \mu \mathrm{M}), 1 \mu$ l of DNA template,

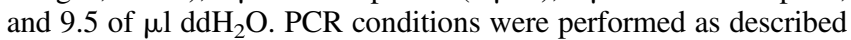
by $\mathrm{Cao}$ et al. (2019a). PCR products were purified and sequenced by SinoGenoMax Co. Ltd. (Chinese National Human Genome Center, Beijing, China).

Phylogenetic analyses. The forward and reverse sequences were assembled to generate consistent sequences using MEGA version 6.0. All sequences were blasted in GenBank. Multiple sequence alignments of each gene were made with ClustalW (as implemented in MEGA 6.0) and edited manually as necessary. The sequences were deposited in GenBank (Supplementary Table S1). Bayesian inference (BI) was used to construct a phylogenetic tree with MrBayes version 3.2.6 (Ronquist et al. 2012). For the isolates from the gloeosporioides complex, two concatenated datasets (with or without ApMat gene sequences) were generated because some of the type strains in the gloeosporioides species complex did not have the ApMat gene region. MrModeltest version 2.3 (Nylander 2004), as implemented in MrMTgui, was used to determine the best-fit model of nucleotide substitution for each genomic locus using the corrected Akaike information criterion. For the gloeosporioides species complex, the following nucleotide substitution models were used: $\mathrm{SYM}+\mathrm{I}+\mathrm{G}$ for ITS, HKY+I for $G A P D H, \mathrm{GTR}+\mathrm{G}$ for $A C T$ and $T U B 2, \mathrm{~K} 80+\mathrm{I}+\mathrm{G}$ for $C H S-1$, and $\mathrm{HKY}+\mathrm{G}$ for ApMat. For the boninense species complex, the following models were used: $\mathrm{SYM}+\mathrm{I}+\mathrm{G}$ for ITS, $\mathrm{HKY}+\mathrm{G}$ for $G A P D H, \mathrm{GTR}+\mathrm{G}$ for $A C T$, GTR+I for $T U B 2$, and $\mathrm{K} 80+\mathrm{G}$ for $C H S$-1. Eight simultaneous Markov Chain Monte Carlo chains were run from random trees with $6 \times 10^{6}$ generations for the gloeosporioides species complex and $3 \times 10^{6}$ for the boninense species complex with the trees were sampled every 1,000 generations. The first $25 \%$ of trees were discarded as burn-in and the remaining sampled trees were used to calculate posterior probabilities (PPs). In addition, maximum likelihood (ML) analyses

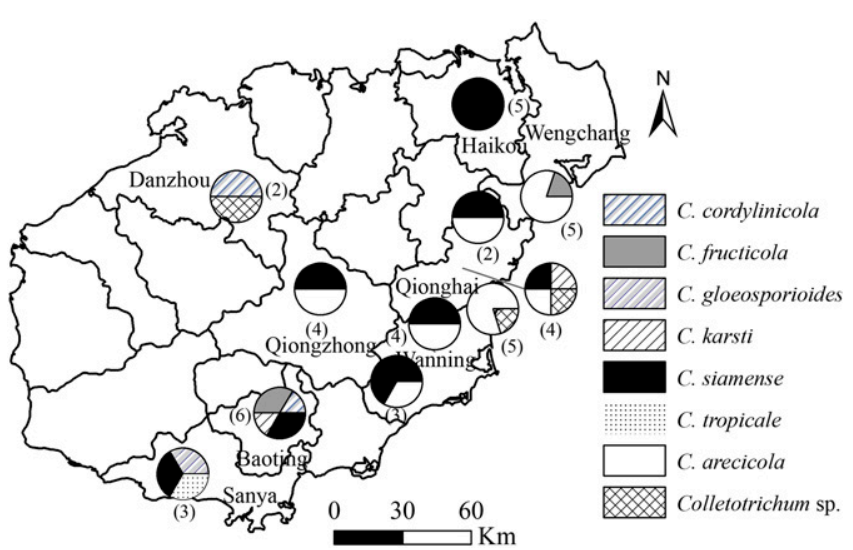

Fig. 1. Map of locations and compositions of Colletotrichum spp. isolates sampled in Hainan, China. Numerals in parentheses indicate the number of isolates obtained from that areca palm plantation. of the multilocus alignments were performed using RaxmlGUI version 1.3.1 (Silvestro and Michalak 2012). A GTRGAMMAI substitution model was applied with 1,000 bootstrap replicates.

To clearly identify the genes and/or loci in which variation is responsible for differentiating the new species, all six loci (ITS, $A C T, C H S-1, G A P D H, T U B 2$, and ApMat) were analyzed individually for the isolates from the gloeosporioides species complex using BI and ML methods.

Alignments and tree files derived in this study were deposited in TreeBASE (https://www.treebase.org/treebase-web/home.html; accession number S25099).

Morphological analysis. Morphological and cultural characterizations were conducted based on published methods (Cai et al. 2009) and hence are only described briefly. Mycelial discs (5-mm diameter), taken from the edge of 5-day-old colonies in PDA, were transferred onto fresh PDA and incubated at $25^{\circ} \mathrm{C}$ with a $12 / 12-\mathrm{h}$ fluorescent light/dark cycle. There were three replicate plates for each isolate. Colony diameters were measured daily for 5 days to calculate mean daily growth (in millimeters per day). The shape, color, and density of colonies were recorded after 5 days of incubation. Appressoria were induced using a published slide culture technique (Cai et al. 2009). The shapes and sizes of conidia and appressoria were assessed under a digital microscope (Eclipse 80i; Nikon, Tokyo, Japan) and 30 conidia and appressoria selected randomly were recorded for each strain. For the new species, morphological and cultural characteristics of the holotype on oatmeal agar (OA) and synthetic nutrient-poor agar medium (SNA) were recorded.

Prevalence of Colletotrichum species. The prevalence of each Colletotrichum species was calculated as $(N s / N t) \times 100 \%$, where $N s$ is the number of leaf samples yielding at least one isolate of the species concerned and $N t$ is the number of leaf samples examined.

Pathogenicity tests. Fourteen Colletotrichum isolates, comprising one isolate from each of $C$. tropicale and C. gloeosporioides (as only one isolate was obtained for these two species) and two isolates from each of the other six species, were tested for their pathogenicity against detached tender healthy leaves (the youngest fully expanded leaves) of areca palm (cultivar Reyan 1) using both nonwound and wound inoculation methods. The tested leaves were washed three times with sterile water and air-dried on pieces of sterilized filter paper. For the wound inoculation method, the leaves were punctured with a sterilized needle $(0.5$-mm diameter) and hyphal plugs (5$\mathrm{mm}$ diameter) from actively growing margins of PDA cultures were then placed onto each wound site. For the method of nonwound inoculation, hyphal plugs from actively growing margins of PDA cultures were placed on the leaves without wounding. Leaves, inoculated with sterile PDA plugs onto the wound or nonwound, were treated as the controls. After inoculation, the leaves were placed onto pieces of moist tissue papers in sterilized plastic containers. The containers were sealed in plastic and maintained in a chamber at $25^{\circ} \mathrm{C}$ with a 12/12-h light/dark regime. Lesion diameter was measured across two perpendicular directions 11 days after inoculation for the wound-inoculated leaves, whereas the leaves inoculated without wounding were assessed 30 days after inoculation. A completely randomized design was used with three replicates per isolate; there were three leaves in each replicate with two inoculation points per leaf.

Data analysis. One-way analysis of variance was used to compare the sizes of conidia and appressoria, growth rates among species, and lesion diameters (averaged over the two perpendicular directions) among isolates tested, and means were compared based on the Fisher's least significant difference test. SAS software (version 8.0; SAS Institute, Cary, NC) was used.

\section{Results}

Phylogenetic analyses and species identification. Forty-three Colletotrichum isolates (two to six isolates for each plantation sampled) were obtained from 55 leaf samples. Based on the morphology and BLAST search in GenBank, 41 isolates were identified as belonging to the gloeosporioides species complex and the other two 
to the boninense species complex. The six-gene (ITS, ACT, CHS-1, $G A P D H, T U B 2$, and ApMat) and the five-gene (ITS, ACT, CHS-1, $G A P D H$, and TUB2) alignment of the gloeosporioides species complex contained 3,264 characters including gaps with the 1,539 unique site patterns and 2,264 characters including gaps with the 925 unique site patterns, respectively. The combined gene (ITS, ACT, CHS-1, $G A P D H$, and $T U B 2$ ) alignment of the boninense species complex comprised 2,213 characters including gaps with the 576 unique site patterns. The ML tree confirmed the tree topology from the Bayesian analysis.

In the six-gene tree, the 41 isolates in the gloeosporioides species complex clustered into seven clades as follows: two with C. cordylinicola (3.6\% of the samples examined; Bayesian PP value, 0.97; RAxML bootstrap support ML value, 60), three with $C$. fructicola (5.5\%; PP, 0.94; ML, 95), 16 with C. siamense (29.1\%; PP, 1; ML, 90), one with C. gloeosporioides (1.8\%; PP, 1; ML, 100), one with $C$. tropicale $(1.8 \%$; PP, 1 ; ML, 84$)$, and three Colletotrichum sp. clustered with $C$. ledongense and $C$. syzygicola (5.5\%). In addition, 15 isolates $(27.3 \%$ of the samples examined; closely related to $C$. cordylinicola) were clustered distantly from any known species in the complex (PP, 1; ML, 93) and are herein described as a new species, C. arecicola (Fig. 2). Although the topology of the five-gene tree of the gloeosporioides species complex was similar to that of the six-gene tree (Fig. 3), the five-gene trees failed to delimit C.cordylinicola, $C$. arecicola, and Colletotrichum sp. Furthermore, support for the $C$. siamense clade $(\mathrm{PP}<0.9 ; \mathrm{ML}<50)$ and the $C$. fructicola clade $(\mathrm{PP}<0.9 ; \mathrm{ML}=89)$ was low in the five-gene tree. The two isolates in the boninense species complex were clustered with $C$. karstii $(3.6 \%$ of the samples examined; PP, 1; ML, 94) (Fig. 4).

Single-locus phylogenetic analyses of the isolates from the gloeosporioides species complex showed that all seven species in this study could be delimited from the other species using the ApMat gene sequences only, although the $C$. arecicola isolates were separated into two distinct clades (Supplementary Fig. S1). No more than three of the seven species could be differentiated when each of the other sequences (ITS, ACT, CHS-1, GAPDH, and TUB2) was used individually.

Taxonomy. Based on the morphology and phylogenetic analysis, the 43 Colletotrichum isolates from areca palm in Hainan were identified to be from eight species, including one new species that is described below.

Colletotrichum arecicola X.R. Cao, H.Y. Che \& D.Q. Luo, sp. nov. - MycoBank MB 831251; Figure 5.

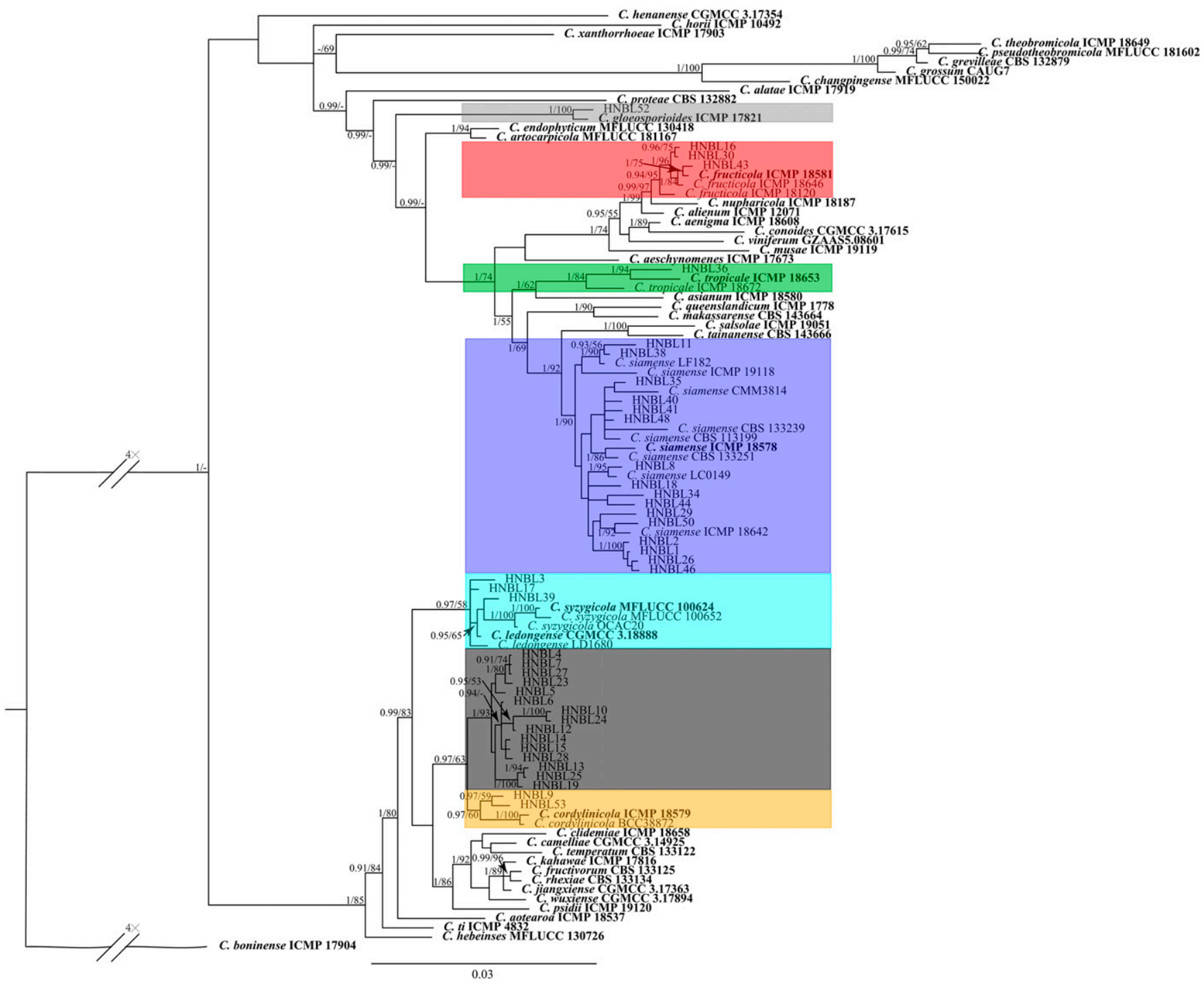

Fig. 2. A Bayesian inference phylogenetic tree based on concatenated sequences of internal transcribed spacer (ITS), actin (ACT), chitin synthase 1 (CHS-1), glyceraldehyde-3phosphate dehydrogenase (GAPDH), $\beta$-tubulin (TUB2), and mating type locus MAT1-2 (ApMat) to illustrate the relationships of Colletotrichum spp. isolates within the gloeosporioides species complex. The species $C$. boninense (ICMP 17904) was used as an outgroup. The Markov chain was run for $6 \times 10^{6}$ generations, each locus with a separate model of DNA evolution. Bayesian posterior probability values $\geq 0.90$ and RAxML bootstrap support values (maximum likelihood $\geq 50 \%$ ) are shown at the nodes. Ex-type isolates are in bold. Shaded blocks indicate clades containing isolates obtained from areca palm in this study. 
Etymology. Referring to the name of the host (Areca catechu) where the species was first collected.

Sexual morph was not observed. Asexual morph developed on PDA. Colonies on PDA $67 \mathrm{~mm}$ in diameter after 5 days at $25^{\circ} \mathrm{C}$, with white to dark gray colonies with dense aerial mycelium; chlamydospores were not observed. Vegetative hyphae were hyaline, smooth-walled, septate, and branched. Conidiomata and setae were not observed. Conidiophores formed directly on aerial mycelium, hyaline, smooth-walled, septate, and branched. Conidiogenous cells were hyaline, smooth-walled, cylindrical to ampulliform, 9 to $22 \times 2$ to $4.5 \mu \mathrm{m}$, apex 1 to $3 \mu \mathrm{m}$ in diameter. Conidia were hyaline, smoothwalled, aseptate, straight, cylindrical to clavate, with both ends round or one end round and one end slightly acute, 10.5 to $16.0 \times 4$ to $6 \mu \mathrm{m}$ (mean dimensions $\pm \mathrm{SD}=13.9 \pm 1.2 \times 4.9 \pm 0.4 \mu \mathrm{m}$ ), length/width $(\mathrm{L} / \mathrm{W})$ ratio $=2.8$. Appressoria were solitary, brown to dark brown, variable in shape, irregular or knobbed, 12 to $20 \times 5$ to $8 \mu \mathrm{m}$ (mean dimensions $\pm \mathrm{SD}=14.9 \pm 2.3 \times 6.2 \pm 0.7 \mu \mathrm{m}), \mathrm{L} / \mathrm{W}$ ratio $=2.4$.
Asexual morph developed on OA. Setae were observed in the acervuli about 40 to $80 \mu \mathrm{m}$ long. Conidiophores were hyaline to pale smooth-walled, septate, and branched. Conidiogenous cells were hyaline to pale brown, cylindrical to clavate, 12 to $30 \times 2$ to $5 \mu \mathrm{m}$, apex 1 to $3.5 \mu \mathrm{m}$ in diameter. Conidia were hyaline, smooth-walled, aseptate, straight, cylindrical, both ends rounded, 11 to $17.5 \times 3.5$ to $6 \mu \mathrm{m}$ (mean dimensions $\pm \mathrm{SD}=13.8 \pm 1.4 \times 4.9 \pm 0.4 \mu \mathrm{m}), \mathrm{L} / \mathrm{W}$ ratio $=$ 2.8. Appressoria were solitary, brown to dark brown, cylindric to elliptic in shape, 7 to $13 \times 5$ to $8 \mu \mathrm{m}$ (mean dimensions $\pm \mathrm{SD}=9.0 \pm$ $1.3 \times 6.3 \pm 0.6 \mu \mathrm{m}), \mathrm{L} / \mathrm{W}$ ratio $=1.4$.

Asexual morph developed on SNA. Setae were dark brown to black, opaque, tip acute, base cylindrical, and 35 to $90 \mu \mathrm{m}$ long. Conidiophores were hyaline, smooth-walled, septate, and branched. Conidiogenous cells were hyaline, clavate, 8 to $23 \times 2$ to $4.5 \mu \mathrm{m}$, apex 1 to $2.5 \mu \mathrm{m}$ in diameter. Conidia were hyaline, smoothwalled, aseptate, cylindrical, both ends rounded, 10.5 to $16.5 \times 3.5$ to $6 \mu \mathrm{m}($ mean $\pm \mathrm{SD}=14.3 \pm 1.2 \times 4.8 \pm 0.5 \mu \mathrm{m}), \mathrm{L} / \mathrm{W}$ ratio $=3.0$.

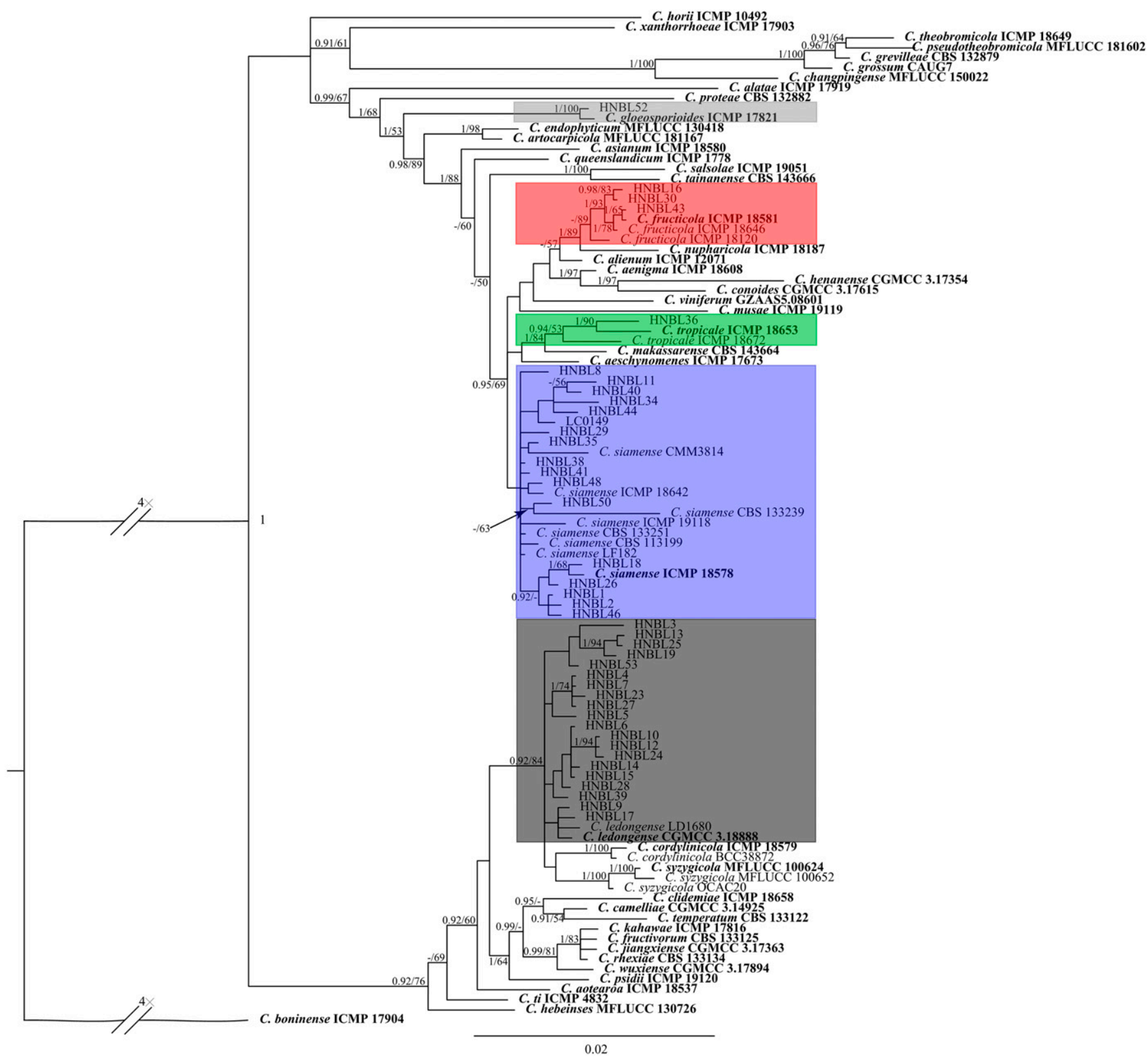

Fig. 3. A Bayesian inference phylogenetic tree based on concatenated sequences of internal transcribed spacer (ITS), actin (ACT), chitin synthase 1 (CHS-1), glyceraldehyde-3phosphate dehydrogenase (GAPDH), and $\beta$-tubulin (TUB2) to illustrate the relationships of Colletotrichum spp. isolates within the gloeosporioides species complex. The species $C$. boninense (ICMP 17904) was used as an outgroup. The Markov chain was run for $6 \times 10^{6}$ generations, each locus with a separate model of DNA evolution. Bayesian posterior probability values $\geq 0.90$ and RAxML bootstrap support values (maximum likelihood $\geq 50 \%$ ) are shown at the nodes. Ex-type isolates are in bold. Shaded blocks indicate clades containing isolates obtained from areca palm in this study. 


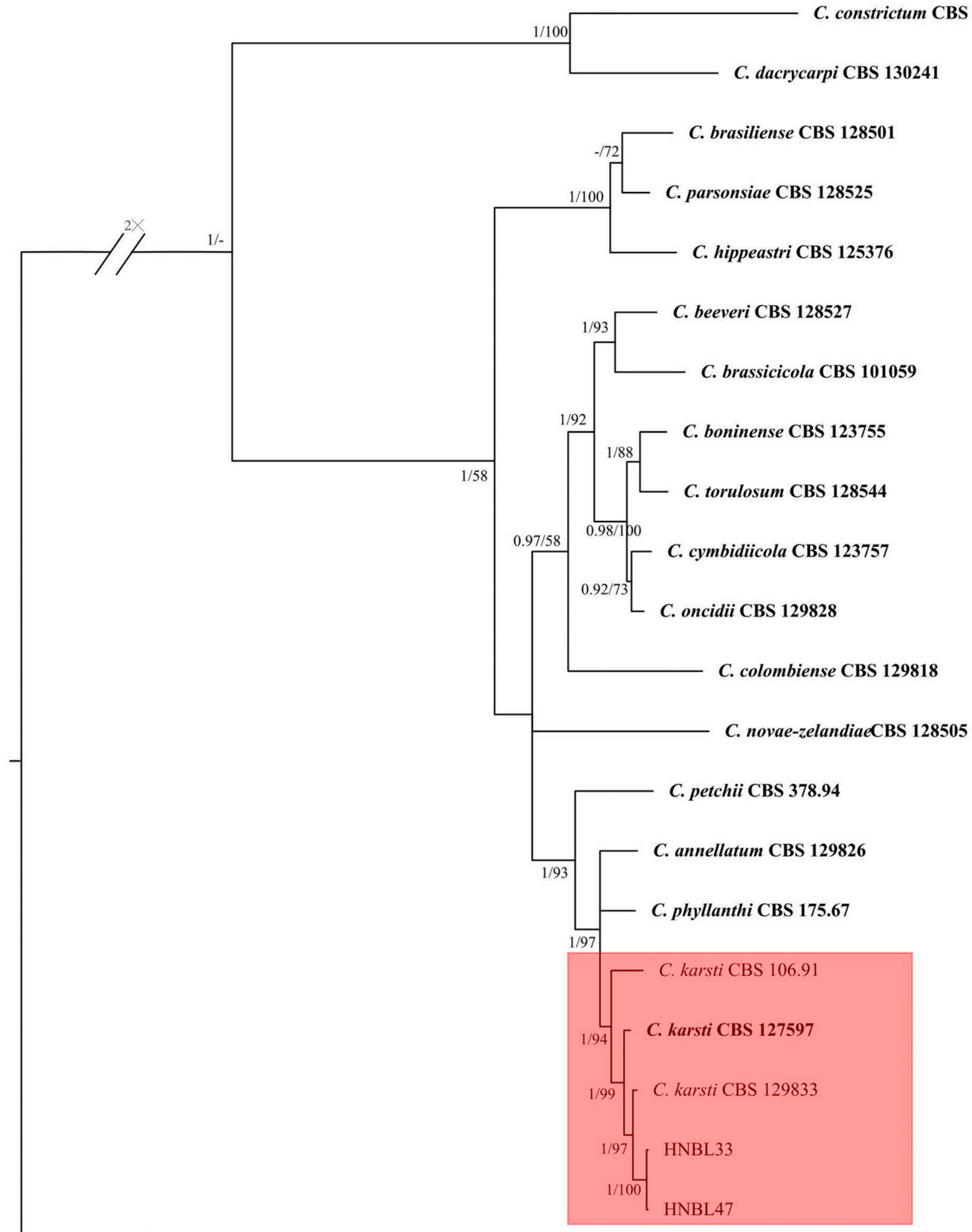

ICMP 17821C. gloeosporioides

0.04

Fig. 4. A Bayesian inference phylogenetic tree based on concatenated sequences of internal transcribed spacer (ITS), actin (ACT), chitin synthase 1 (CHS-1), glyceraldehyde-3phosphate dehydrogenase (GAPDH), and $\beta$-tubulin (TUB2) to illustrate the relationships of Colletotrichum spp. isolates within the boninense species complex. The species $C$. gloeosporioides (ICMP 17821) was used as an outgroup. The Markov chain was run for $3 \times 10^{6}$ generations, each locus with a separate model of DNA evolution. Bayesian posterior probability values $\geq 0.90$ and RAxML bootstrap support values (maximum likelihood $\geq 50 \%$ ) are shown at the nodes. Ex-type isolates are in bold. Shaded blocks indicate clades containing isolates obtained from areca palm in this study. 
Appressoria were dark brown, simple, irregular in shape, or bullet-shaped with an acute tip, sometimes irregularly lobed, 9 to $18 \times 4$ to $9.5 \mu \mathrm{m}($ mean $\pm \mathrm{SD}=13.1 \pm 2.1 \times 6.8 \pm 1.3 \mu \mathrm{m})$, $\mathrm{L} / \mathrm{W}$ ratio $=1.9$.

Holotype (HMAS 248158): China, Hainan Province, Wenchang city, on a diseased areca palm leaf (A. catechu), March. 2019, X.R. Cao, ex-type living culture CGMCC 3.19667 = HNBL5.

Notes: This new species was isolated from infected leaves of areca palm collected from four counties in Hainan, China; it was phylogenetically most closely related to C. cordylinicola (Fig. 2). Phylogenetic analyses showed that isolates from $C$. arecicola could be delimited from other species in the gloeosporioides species complex using the ApMat locus although the $C$. arecicola isolates were separated into two distinct clades (Supplementary Fig. S1). In morphology, $C$. arecicola differs from $C$. cordylinicola by having longer appressoria (12 to $20 \times 5$ to $8 \mu \mathrm{m}$ versus 13 to $13.4 \times 7.2$ to $7.3 \mu \mathrm{m})$ and knobbed appressoria on PDA.

Morphological characterization. All seven species from the gloeosporioides species complex developed white to gray or black colonies with dense aerial mycelia, whereas isolates of $C$. karstii from the boninense species complex developed white colonies with sparse aerial mycelia (Table 1). The width of $C$. karstii conidia was significantly $(P<0.01)$ larger than the other species, whereas the growth rate of $C$. karstii was slower $(P<0.01)$ than the other species (Table 1). There were also significant differences $(P<0.01)$ in the size of both conidia and appressoria and in growth rates among species within the gloeosporioides species complex.

Pathogenicity tests. Inoculation of wounded areca palm leaves (cultivar Reyan 1) resulted in typical symptoms of anthracnose for all tested isolates; the average lesion diameter ranged from 1.8 to
$4.0 \mathrm{~mm}$ (Fig. 6). There were significant differences $(P<0.01)$ in the lesion diameter among species. Isolates of $C$. arecicola and $C$. cordylinicola resulted in larger lesions (diameter $>3 \mathrm{~mm}$ ), whereas isolates of $C$. karsti and C. tropicale produced smaller lesions (diameter $<2 \mathrm{~mm}$ ). There was also a significant difference between the lesion diameter two $C$. siamense isolates $(2.3$ and $3.2 \mathrm{~mm})$. However, no symptoms were observed on those leaves inoculated without wounding 30 days after inoculation.

\section{Discussion}

The Colletotrichum species associated with anthracnose of areca palm in Hainan, China, were identified based on morphological characteristics and multilocus phylogenetic analyses. Eight Colletotrichum species (C. cordylinicola, C. fructicola, C. gloeosporioides, C. siamense, $C$. tropicale, an unknown species Colletotrichum sp., a new species $C$. arecicola from the gloeosporioides species complex, and $C$. karstii from the boninense species complex) were shown to be associated with anthracnose of areca palm in Hainan.

Species in the gloeosporioides species complex were previously reported to cause anthracnose on numerous plants worldwide, particularly in the tropical region (Freeman et al. 1998; Udayanga et al. 2013). More than $74.5 \%$ of the isolates obtained in this study were from the gloeosporioides species complex. This was in agreement with previous reports that $C$. gloeosporioides was the causal agent of anthracnose of areca palm in India and Hainan (Yashoda et al. 1992; Zhu et al. 2015). However, this study also indicated that a species belonging to the boninense species complex can cause anthracnose on areca palm.

C. siamense, C. fructicola, C. tropicale, and C. karstii were reported on several host plants in Hainan. For example, both $C$. siamense and
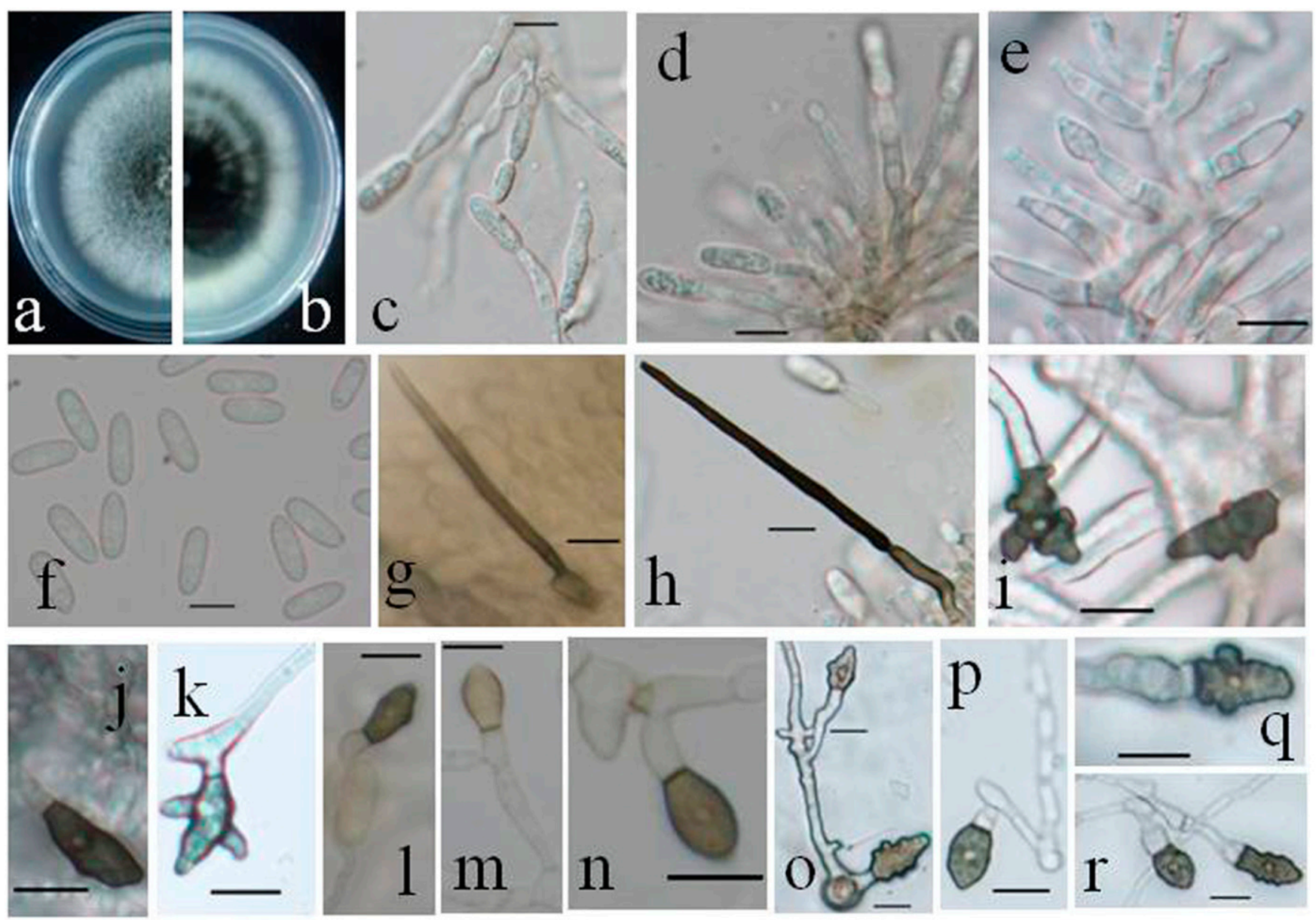

Fig. 5. Culture characteristics and microscopic features of the Colletotrichum arecicola sp. nov. a and b, Colonies on potato dextrose agar (PDA) above and below. c, $\mathbf{d}$, and $\mathbf{e}$, Conidiophores. f, Conidia. $\mathbf{g}$ and h, Setae. i, j, k, l, m, n, o, p, q, and r, Appressoria. c, f, and i to k were produced on PDA; g, l, and $\mathrm{m}$ were produced on oatmeal agar; and h and 0 to $r$ were produced on synthetic nutrient-poor agar medium. Scale bars $=10 \mu \mathrm{m}$. 
C. fructicola were reported on tea-oil trees, rubber trees, and coffee (Cao et al. 2019a, b). In addition, $C$. siamense was reported on mango, partridge tea, and red gragon (Liu et al. 2018a; Qin et al. 2017; Zhao et al. 2018); C. fructicola on strawberry (Jayawardena et al. 2016); C. tropicale on Sauropus androgynus and coffee (Cao et al. 2019b; Liu et al. 2018b); and C. karstii on chili, stylo, and coffee (Cao et al. 2019b; Diao et al. 2017; Jia et al. 2017). In this study, these four species were isolated from areca palm in Hainan in 8,2, and 2 plantations of the 11 plantations sampled in Hainan, respectively (Fig. 1). In addition, $C$. siamense was the most common species associated with areca palm in Hainan. Similar results were obtained on rubber tree and coffee in Hainan (Cao et al. 2019a, b). Further research is needed to study whether $C$. siamense from areca palm, rubber tree, and coffee can cross-infect each other, as they are usually planted adjacent to or intercropped with each other in Hainan.

C. cordylinicola was isolated from leaves of Cordyline fruticosa and Eugenia javanica in Thailand and Laos (Phoulivong et al. 2010). It is herein reported in Hainan for the first time, although with low frequencies $(3.6 \%)$ on areca palm. The new species, $C$. arecicola, was a common pathogen on areca palm in Hainan, present in 7 of the 11 areca plantations sampled. The unknown Colletotrichum sp. was clustered with $C$. ledongense and $C$. syzygicola; further research is needed to determine its taxonomical identity.

The resolution of Colletotrichum species differs depending on both the locus used and the species concerned; thus, there is no general agreement on the locus or loci to use for species identification (Marin-Felix et al. 2017). The ApMat locus was proven to be better in delimiting the gloeosporioides species complex than $A C T, C A L$, GAPDH, GS, ITS, and TUB2 (Liu et al. 2015; Sharma et al. 2013; Silva et al. 2012). All seven species in the gloeosporioides species complex obtained in this study can be differentiated from the other species when using ApMat sequences only. However, Liu et al. (2015) reported that ApMat should be combined with other loci for species delimitation in the gloeosporioides complex. In this study, the $C$. arecicola isolates were separated into two distinct clades when using the ApMat locus only. The isolates identified as $C$. cordylinicola, C. arecicola, and Colletotrichum sp. in the six-gene tree could not be delimited in the five-gene tree without the ApMat gene. Furthermore, both the $C$. siamense clade and the $C$. fructicola clade did not receive high support values in the five-gene tree without the ApMat gene, consistent with a previous report (de Silva et al. 2019).

Wounding is known to enhance infection by Colletotrichum species and subsequent disease development; thus, many studies of Colletotrichum spp. have been carried out in the laboratory using wound-based inoculation methods (Peres et al. 2005). In this study, all eight species were able to infect wounded detached areca palm leaves.

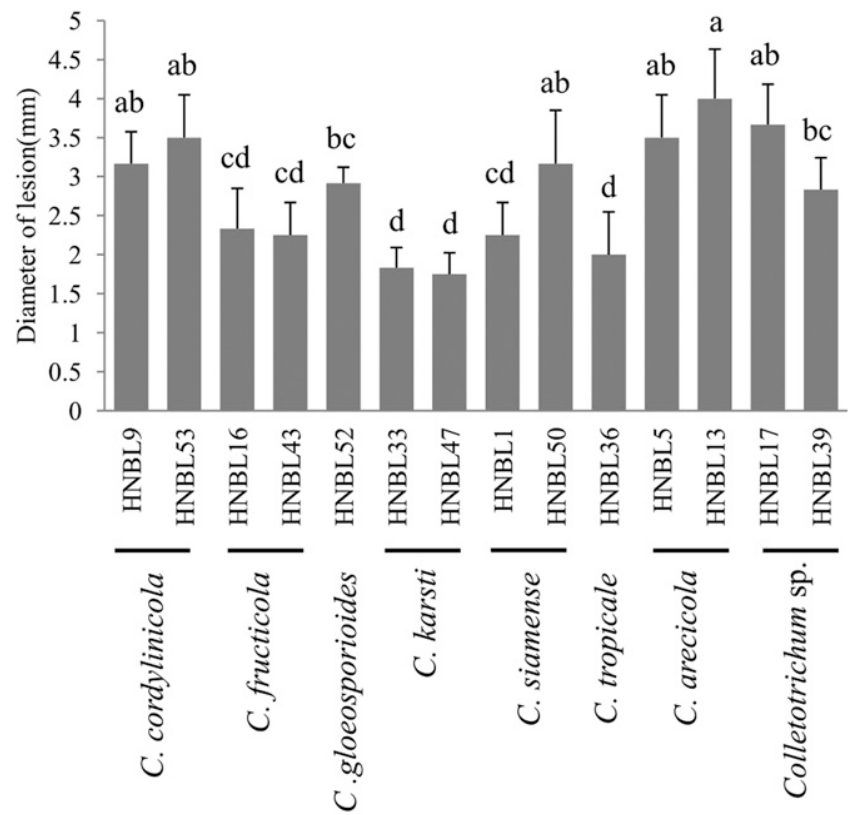

Fig. 6. Lesion diameters of Colletotrichum isolates on wounded leaves of areca palm (cultivar Reyan 1) 11 days after inoculation. The bars represent the standard error, and columns with the same letter do not differ significantly according to the Fisher's least significant difference test $(P=0.05)$.

Table 1. Morphological and cultural characteristics of Colletotrichum spp. causing anthracnose of areca palm in Hainan, China ${ }^{\mathrm{z}}$

\begin{tabular}{|c|c|c|c|c|c|c|c|c|}
\hline \multirow[b]{2}{*}{ Species } & \multirow{2}{*}{$\begin{array}{c}\text { Colony } \\
\text { characteristics }\end{array}$} & \multicolumn{3}{|c|}{ Conidia } & \multicolumn{3}{|c|}{ Appressoria } & \multirow{2}{*}{$\begin{array}{c}\text { Growth rates } \\
(\mathbf{m m} / \text { day })\end{array}$} \\
\hline & & Shape & Length $(\mu \mathrm{m})$ & Width $(\mu \mathrm{m})$ & Shape & Length $(\mu \mathrm{m})$ & Width $(\mu \mathrm{m})$ & \\
\hline C. cordylinicola & $\begin{array}{l}\text { White with gray in } \\
\text { center colony, } \\
\text { dense mycelium }\end{array}$ & Cylindrical & $\begin{array}{c}14.0 \pm 0.17 \\
(10.5-16.5) \mathrm{c}\end{array}$ & $\begin{array}{l}4.7 \pm 0.03 \\
(4.0-5.5) \mathrm{d}\end{array}$ & $\begin{array}{l}\text { Ovoid, clavate, or } \\
\text { slightly irregular }\end{array}$ & $\begin{array}{c}12.6 \pm 0.3 \\
(8.5-17.5) \mathrm{bc}\end{array}$ & $\begin{array}{c}6.4 \pm 0.1 \\
(5.0-9.0) \mathrm{cd}\end{array}$ & $12.7 \pm 0.5 b$ \\
\hline C. fructicola & $\begin{array}{l}\text { White with gray to } \\
\text { black in center, } \\
\text { dense mycelium, } \\
\text { with orange } \\
\text { conidial masses }\end{array}$ & Cylindrical & $\begin{array}{c}14.2 \pm 0.2 \\
(12.0-16.5) b c\end{array}$ & $\begin{array}{c}5.0 \pm 0.06 \\
(3.5-6.0) b\end{array}$ & $\begin{array}{l}\text { Ovoid, clavate, or } \\
\text { slightly irregular }\end{array}$ & $\begin{array}{c}11.2 \pm 0.5 \\
(7.5-16.0) \mathrm{de}\end{array}$ & $\begin{array}{c}6.7 \pm 0.2 \\
(5.0-9.0) \mathrm{bc}\end{array}$ & $12.8 \pm 0.2 \mathrm{~b}$ \\
\hline C. gloeosporioides & $\begin{array}{l}\text { White to gray } \\
\text { colony, dense } \\
\text { mycelium, with } \\
\text { orange conidial } \\
\text { masses }\end{array}$ & Cylindrical & $\begin{array}{c}15.4 \pm 0.2 \\
(13.5-18.0) \mathrm{a}\end{array}$ & $\begin{array}{c}4.8 \pm 0.05 \\
(4.0-5.5) \mathrm{cd}\end{array}$ & $\begin{array}{l}\text { Clavate or slightly } \\
\text { irregular }\end{array}$ & $\begin{array}{c}12.0 \pm 0.5 \\
(8.5-16.5) \mathrm{cd}\end{array}$ & $\begin{array}{c}6.4 \pm 0.2 \\
(5.0-8.0) \mathrm{cd}\end{array}$ & $14.6 \pm 0.2 \mathrm{a}$ \\
\hline C. karsti & $\begin{array}{l}\text { White colony, } \\
\text { sparse mycelium }\end{array}$ & Oblong & $\begin{array}{c}14.7 \pm 0.2 \\
(12.0-18.5) \mathrm{b}\end{array}$ & $\begin{array}{l}7.0 \pm 0.05 \\
(6.0-8.5) \mathrm{a}\end{array}$ & Globose or ovoid & $\begin{array}{c}9.8 \pm 0.2 \\
(7.0-14.5) \mathrm{f}\end{array}$ & $\begin{array}{c}7.6 \pm 0.2 \\
(5.5-11.0) \mathrm{a}\end{array}$ & $9.6 \pm 0.1 \mathrm{c}$ \\
\hline C. siamense & $\begin{array}{l}\text { White with gray in } \\
\text { center colony, } \\
\text { dense mycelium, } \\
\text { with orange } \\
\text { conidial masses }\end{array}$ & $\begin{array}{l}\text { Cylindrical to } \\
\text { fusiform }\end{array}$ & $\begin{array}{c}14.3 \pm 0.1 \\
(12.0-16.5) b c\end{array}$ & $\begin{array}{c}4.9 \pm 0.06 \\
(3.5-6.0) \mathrm{bc}\end{array}$ & Ovoid or clavate & $\begin{array}{c}10.7 \pm 0.2 \\
(7.0-16.5) \text { ef }\end{array}$ & $\begin{array}{c}7.0 \pm 0.1 \\
(5.5-9.5) b\end{array}$ & $12.6 \pm 0.3 \mathrm{~b}$ \\
\hline C. tropicale & $\begin{array}{l}\text { White to gray } \\
\text { colony, dense, } \\
\text { with orange } \\
\text { conidial masses }\end{array}$ & Cylindrical & $\begin{array}{c}14.4 \pm 0.2 \\
(12.0-16.5) b c\end{array}$ & $\begin{array}{c}4.9 \pm 0.04 \\
(4.0-5.5) b c\end{array}$ & Subglobose or clavate & $\begin{array}{c}10.4 \pm 0.4 \\
(7.5-14.5) \text { ef }\end{array}$ & $\begin{array}{c}6.7 \pm 0.2 \\
(5.0-9.0) \mathrm{bc}\end{array}$ & $14.8 \pm 0.1 \mathrm{a}$ \\
\hline C. arecicola & $\begin{array}{l}\text { White with gray to } \\
\text { black in center } \\
\text { colony, dense } \\
\text { mycelium }\end{array}$ & $\begin{array}{l}\text { Cylindrical to } \\
\text { clavate }\end{array}$ & $\begin{array}{c}14.3 \pm 0.2 \\
(10.5-16.5) b c\end{array}$ & $\begin{array}{c}4.9 \pm 0.05 \\
(4.0-6.0) b c\end{array}$ & Irregular or knobbed & $\begin{array}{c}15.5 \pm 0.3 \\
(12.0-21.0) \mathrm{a}\end{array}$ & $\begin{array}{c}6.1 \pm 0.1 \\
(5.0-8.0) \text { de }\end{array}$ & $13.4 \pm 0.1 \mathrm{~b}$ \\
\hline Colletotrichum sp. & $\begin{array}{l}\text { White to gray } \\
\text { colony, dense } \\
\text { mycelium, with } \\
\text { orange conidial } \\
\text { masses }\end{array}$ & $\begin{array}{l}\text { Cylindrical to } \\
\text { fusiform }\end{array}$ & $\begin{array}{c}14.7 \pm 0.2 \\
(12.5-17.5) \mathrm{b}\end{array}$ & $\begin{array}{c}4.8 \pm 0.04 \\
(4.0-6.0) \mathrm{cd}\end{array}$ & Irregular or knobbed & $\begin{array}{c}13.4 \pm 0.2 \\
(10.0-17.5) b\end{array}$ & $\begin{array}{c}5.9 \pm 0.1 \\
(4.5-9.0) \mathrm{e}\end{array}$ & $13.0 \pm 0.2 b$ \\
\hline
\end{tabular}

\footnotetext{
${ }^{\mathrm{z}}$ Values within the same column followed by the same letters are not significantly different based on the one-way analysis of variance with Fisher's least sig-
} nificant difference test at $P=0.05$. 
Overall, the isolates from the gloeosporioides species complex caused larger lesions than those of $C$. karstii. There were also significant differences in the pathogenicity among species within the gloeosporioides species complex. Generally, isolates from $C$. arecicola, $C$. siamense, and $C$. cordylinicola were found to cause larger lesions than other species. The former two species accounted for 27.3 and $29.1 \%$ of the isolates obtained from the 11 plantations in this study, respectively. The two $C$. siamense isolates also differed in lesion diameter, indicating the presence of intraspecies variability in the aggressiveness on areca palm. Similarly, such intraspecies variability in $C$. siamense was also observed on mango leaves and fruits (Mo et al. 2018). In three Colletotrichum spp., different pathotypes were identified on mature green and ripe chili fruit (Mongkolporn et al. 2010).

No visual symptoms were observed on those leaves when inoculated without wounding. Previous studies suggested that wounding is necessary for Colletotrichum species to infect various hosts, such as mango fruit (Freeman and Shabi 1996; Lima et al. 2013) and grape leaf (Hong et al. 2008). When 12 Colletotrichum species from cultivated pear were inoculated onto detached pear leaves, only two species were pathogenic to those leaves without wounding ( $\mathrm{Fu}$ et al. 2019). This phenomenon may be related to the quiescent infection, which is an important feature of Colletotrichum spp. (Peres et al. 2005). The cuticle and epidermis may also act as a barrier to infection by Colletotrichum spp. (Auyong et al. 2015). Factors such as inoculum density, temperature, wetness duration, and plant age could influence the infection by Colletotrichum spp. and subsequent symptom development (Freeman et al. 1998; Hong and Hwang 1998; Uysal and Kurt 2017).

In 10 of the 11 areca palm plantations sampled, at least two Colletotrichum species were present, and the composition of Colletotrichum species varied greatly among the sampled plantations. Fungicide is one of the main strategies for areca palm anthracnose management (Li 2011; Nidhina and Hegde, 2014); however, different Colletotrichum species display different sensitivities to individual fungicides (Cao et al. 2019b; Chen et al. 2016). Therefore, it is essential to determine the species in a given plantation in order to maximize fungicide control efficacies.

\section{Acknowledgments}

We thank Dr. Fang Liu for help with the phylogenetic analyses.

\section{Literature Cited}

Auyong, A. S. M., Ford, R., and Taylor, P. W. J. 2015. The role of cutinase and its impact on pathogenicity of Colletotrichum truncatum. J. Plant Pathol. Microbiol. 6:259-269.

Cai, L., Hyde, K. D., Taylor, P. W. J., Weir, B., Waller, J. M., Abang, M. M., Zang, J. C., Yang, Y. L., Phouliyong, S., Prihastuti, Z. Y., Shivas, R. G., McKenzie, E. H. C., and Johnston, P. R. 2009. A polyphasic approach for studying Colletotrichum. Fungal Divers. 39:183-204.

Cao, X. R., Xu, X. M., Che, H. Y., West, J. S., and Luo, D. Q. 2019a. Three Colletotrichum species, including a new species, are associated to leaf anthracnose of rubber tree in Hainan, China. Plant Dis. 103:117-124.

Cao, X. R., Xu, X. M., Che, H. Y., West, J. S., and Luo, D. Q. 2019 b. Characteristics and distribution of Colletotrichum species in coffee plantations in Hainan, China. Plant Pathol. 68:1146-1156.

Carbone, I., and Kohn, L. M. 1999. A method for designing primer sets for speciation studies in filamentous ascomycetes. Mycologia 91:553-556.

Chen, S. N., Luo, C. X., Hu, M. J., and Schnabel, G. 2016. Sensitivity of Colletotrichum species, including C. fioriniae and C. nymphaeae, from peach to demethylation inhibitor fungicides. Plant Dis. 100:2434-2441.

de Silva, D. D., Groenewald, J. Z., Crous, P. W., Ades, P. K., Nasruddin, A., Mongkolporn, O., and Taylor, P. W. 2019. Identification, prevalence and pathogenicity of Colletotrichum species causing anthracnose of Capsicum annuum in Asia. IMA Fungus 10:8.

Diao, Y. Z., Zhang, C., Liu, F., Wang, W. Z., Liu, L., Cai, L., and Liu, X. L. 2017. Colletotrichum species causing anthracnose disease of chili in China. Persoonia 38:20-37.

Freeman, S., Katan, T., and Shabi, E. 1998. Characterization of Colletotrichum species responsible for anthracnose diseases of various fruits. Plant Dis. 82: 596-605.

Freeman, S., and Shabi, E. 1996. Cross-infection of subtropical and temperate fruits by Colletotrichum species from various hosts. Physiol. Mol. Plant Pathol. 49:395-404.
Fu, M., Crous, P. W., Bai, Q., Zhang, P. F., Xiang, J., Guo, Y. S., Zhao, F. F. Yang, M. M., Hong, N., Xu, W. X., and Wang, G. P. 2019. Colletotrichum species associated with anthracnose of Pyrus spp. in China. Persoonia 42: $1-35$

Gardes, M., and Bruns, T. D. 1993. ITS primers with enhanced specificity for basidiomycetes - application to the identification of mycorrhizae and rusts. Mol. Ecol. 2:113-118.

Glass, N. L., and Donaldson, G. C. 1995. Development of primer sets designed for use with the PCR to amplify conserved genes from filamentous ascomycetes. Appl. Environ. Microbiol. 61:1323-1330.

Hong, J. K., and Hwang, B. K. 1998. Influence of inoculum density, wetness duration, plant age, inoculation method, and cultivar resistance on infection of pepper plants by Colletotrichum coccodes. Plant Dis. 82:1079-1083.

Hong, S. K., Kim, W. G., Yun, H. K., and Choi, K. J. 2008. Morphological variations, genetic diversity and pathogenicity of Colletotrichum species causing grape ripe rot in Korea. Plant Pathol. J. 24:269-278.

Huang, H., Huang, H., and Liu, H. 2016. Current situation and management recommendations about betel nut planting in Hainan. Asian Agric. Res. 8:15-17.

Jayawardena, R. S., Huang, J. K., Jin, B. C., Yan, J. Y., Li, X. H., Hyde, K. D. Bahkali, A. H., Yin, S. L., and Zhang, G. Z. 2016. An account of Colletotrichum species associated with strawberry anthracnose in China based on morphology and molecular data. Mycosphere. 7:1147-1163.

Jia, Y. X., Yang, M. X., Wang, H., Luo, L. J., Chen, Z. J., Yu, D. G., and Bai, C. J. 2017. First report of anthracnose on Stylosanthes guianensis caused by Colletotrichum karstii in China. Plant Dis. 101:630.

Ko, T. W., Stephenson, S. L., Bahkali, A. H., and Hyde, K. D. 2011. From morphology to molecular biology: Can we use sequence data to identify fungal endophytes? Fungal Divers. 50:113-120.

Li, Z. 2011. Review on the diseases and insects of betelnut. Chin. J. Trop. Crops 32:1982-1988.

Lima, N. B., de A. Batista, M. V., De Morais, M. A., Barbosa, M. A. G., Michereff, S. J., Hyde, K. D., and Câmara, M. P. S. 2013. Five Colletotrichum species are responsible for mango anthracnose in northeastern Brazil. Fungal Divers. 61: $75-88$.

Liu, F., Weir, B. S., Damm, U., Crous, P. W., Wang, Y., Liu, B., Wang, M., Zhang, M., and Cai, L. 2015. Unravelling Colletotrichum species associated with Camellia: Employing ApMat and GS loci to resolve species in the $C$. gloeosporioides complex. Persoonia 35:63-86.

Liu, T., Chen, D., Liu, Z., and Hou, J. M. 2018a. First report of Colletotrichum siamense causing anthracnose on Partridge tea (Mallotus oblongifolius) in China. Plant Dis. 102:1669.

Liu, T., Chen, D., Liu, Z., and Hou, J. M. 2018b. First report of anthracnose caused by Colletotrichum tropicale on Sauropus androgynus in China. Plant Dis. 102: 2030.

Lokesh, M. S., Suryanarayana, V., Patil, S. V., Palakshappa, M. G., and Gurmurthy, S. B. 2013. Efficacy of new fungitoxicant molecules in management of anthracnose (Colletotrichum gloeosporioides Penz.) of arecanut (Areca catechu L.). Int. J. Plant Protec. 6:217-218.

Manamgoda, D. S., Udayanga, D., Cai, L., Chukeatirote, E., and Hyde, K. D. 2013. Endophytic Colletotrichum from tropical grasses with a new species $C$. endophytica. Fungal Divers. 61:107-115.

Marin-Felix, Y., Groenewald, J. Z., Cai, L., Chen, Q., Marincowitz, S., Barnes, I., Bensch, K., Braun, U., Camporesi, E., Damm, U., De Beer, Z. W., Dissanayake, A., Edwards, J., Giraldo, A., Hernández-Restrepo, M., Hyde, K. D., Jayawardena, R. S., Lombard, L., Luangsa-ard, J., McTaggart, A. R., Rossman, A. Y., Sandoval-Denis, M., Shen, M., Shivas, R. G., Tan, Y. P., van der Linde, E. J., Wingfield, M. J., Wood, A. R., Zhang, J. Q., Zhang, Y., and Crous, P. W. 2017. Genera of phytopathogenic fungi: GOPHY 1. Stud. Mycol. 86:99-216.

Mo, J., Zhao, G., Li, Q., Solangi, G. S., Tang, L., Guo, T., Huang, S., and Hsiang, T. 2018. Identification and characterization of Colletotrichum species associated with mango anthracnose in Guangxi, China. Plant Dis. 102: 1283-1289.

Mongkolporn, O., Montri, P., Supakaew, T., and Taylor, P. W. 2010. Differential reactions on mature green and ripe chili fruit infected by three Colletotrichum spp. Plant Dis. 94:306-310.

Nidhina, K., and Hegde, V. 2014. In vitro screening of biological and chemical agents together on the growth of Colletotrichum gloeosporioides (Penz.) Penz. and Sacc. causing inflorescence die back in arecanut. Arch. Phytopathol. Plant Prot. 47:1905-1911.

Nylander, J. A. A. 2004. MrModeltest v2. Program distributed by the author Evolutionary Biology Centre, Uppsala University, Uppsala, Sweden.

O'Donnell, K., and Cigelnik, E. 1997. Two divergent intragenomic rDNA ITS2 types within a monophyletic lineage of the fungus Fusarium are nonorthologous. Mol. Phylogenet. Evol. 7:103-116.

Peng, W., Liu, Y. J., Wu, N., Sun, T., He, X. Y., Gao, Y. X., and Wu, C. J. 2015 Areca catechu L. (Arecaceae): A review of its traditional uses, botany, phytochemistry, pharmacology and toxicology. J. Ethnopharmacol. 164 340-356.

Peres, N. A., Timmer, L. W., Adaskaveg, J. E., and Correll, J. C. 2005. Life styles of Colletotrichum acutatum. Plant Dis. 89:784-796.

Phoulivong, S., Cai, L., Parinn, N., Chen, H., Abd-Elsalam, K. A., Chukeatirote, E., and Hyde, K. D. 2010. A new species of Colletotrichum from Cordyline 
fruticosa and Eugenia javanica causing anthracnose disease. Mycotaxon 114: 247-257.

Qin, L. P., Huang, S. L., Lin, S. H., and Lin, C. H. 2017. First report of anthracnose of Mangifera indica caused by Colletotrichum siamense in Sanya city in China. Plant Dis. 101:1038.

Ronquist, F., Teslenko, M., van der Mark, P., Ayres, D. L., Darling, A., Höhna, S., Larget, B., Liu, L., Suchard, M. A., and Huelsenbeck, J. P. 2012. MrBayes 3.2: Efficient Bayesian phylogenetic inference and model choice across a large model space. Syst. Boil. 61:539-542.

Sharma, G., Kumar, N., Weir, B. S., Hyde, K. D., and Shenoy, B. D. 2013. The ApMat marker can resolve Colletotrichum species: A case study with Mangifera indica. Fungal Divers. 61:117-138.

Silva, D. N., Talhinhas, P., Várzea, V., Cai, L., Paulo, O. S., and Batista, D. 2012. Application of the Apn2/MAT locus to improve the systematics of the Colletotrichum gloeosporioides complex: An example from coffee (Coffea spp.) hosts. Mycologia 104:396-409.

Silvestro, D., and Michalak, I. 2012. raxmlGUI: A graphical front-end for RAxML. Org. Divers. Evol. 12:335-337.

Srimany, A., George, C., Naik, H. R., Pinto, D. G., Chandrakumar, N., and Pradeep, T. 2016. Developmental patterning and segregation of alkaloids in areca nut (seed of Areca catechu) revealed by magnetic resonance and mass spectrometry imaging. Phytochemistry 125:35-42.

Templeton, M. D., Rikkerink, E. H., Solon, S. L., and Crowhurst, R. N. 1992. Cloning and molecular characterization of the glyceraldehyde-3-phosphate dehydrogenase-encoding gene and cDNA from the plant pathogenic fungus Glomerella cingulata. Gene 122:225-230.

Udayanga, D., Manamgoda, D. S., Liu, X. Z., Chukeatirote, E., and Hyde, K. D. 2013. What are the common anthracnose pathogens of tropical fruits? Fungal Divers. 61:165-179.

Uysal, A., and Kurt, S. 2017. Influence of inoculum density, temperature, wetness duration, and leaf age on infection and development of spinach anthracnose caused by the fungal pathogen Colletotrichum spinaciae. Eur. J. Plant Pathol. 149:1041-1052.

Weir, B. S., Johnston, P. R., and Damm, U. 2012. The Colletotrichum gloeosporioides species complex. Stud. Mycol. 73:115-180.

White, T. J., Bruns, T., Lee, S., and Taylor, J. 1990. Amplification and direct sequencing of fungal ribosomal RNA genes for phylogenetics. Pages 315-322 in: PCR Protocols: A Guide to Methods and Applications. M. A Innis, D. H. Gelfand, and J. J. Sninsky, eds. Academic Press, San Diego, CA.

Yashoda, H., Hegde, R. K., and Kulkami, S. 1992. Biossay of fungicides against anthracnose of arecanut in vitro. Curr. Res. 21:70-71.

Zhao, H. J., Chen, S. C., Chen, Y. F., Zou, C. C., Wang, X. L., Wang, Z. H., Liu, A. R., and Ahammed, G. J. 2018. First report of red gragon fruit (Hylocereus polyrhizus) anthracnose caused by Colletotrichum siamense in China. Plan Dis. 102:1175.

Zhu, H., Song, W. W., Yu, F. Y., Liu, L., and Qin, W. Q. 2015. Identification of pathogen of arecanut anthracnose in Hainan. Acta Agricul. Jiangxi. 27:28-31. 